teaching in Edinburgh, I would not have you suppose that in this respect we stand alone. Many teachers have gone from this to other medical schools and hare carried with them our methods, and have planted them there. And indeed all the medical schools of England and Ireland, as well as those of Scotland, have been making rapid progress in the attempt to raise the standard of attainment in every student of medicine by providing him with increased facilities for study in every department. To those of us who are familiar with the results both of the old and of the new systems of medical education, the great benefit of the newer method is apparent.

But although we have taken the right way in bringing the young mind more and more into direct contact with Nature, we must ask you not to fall into the error of supposing that a practical mode of study can ever supersede the older method by means of lectures. It would be impossible for one mind to observe independently all the facts of any science, even if it had all the means at its command. Ilow much more impossible must it be for any one of you to observe independently the great mass of facts in the many sciences you hare to learn within a limited period of time. In practical studies salient points have to be selected and many others omitted. The systematic lecture must always remain as a systemised exposition in which fucts and principles are arrayed, not in the order thut might be necessary for practical study, but in the order required to produce a lucid conception of the subject. Both methods are necessary to enable the mind to gain a definite knowledge of detail, and a sufficiently wide conception of any science that deals with physical nature.

I have now seen a good many years of student life, and have watched the results of a good many educational experiments, and as the result of the experience, the advice I offer you is to attend all the practical classes you can. Give no heed to their being compulsory or non-compulsory, for with their help you can obtain a kind of education which you never can find in books or get from lectures; and when you leave the unirersity and pass into medical practice you will find the opportunity gone.

\section{NOTES OF A CASE OF CIIOLECYSTOTOMY:} RECOVERY.

BY RLTHERFORD MORISON, F.R.C.S., M.D.Edin., Late Visiting Medical Officer, Hartlepools Hospital, Newcastle-upon-Tyne.

II. P., aged 45, married, was tine mother of six living children, and had had four miscarriages. The patient was an active, intelligent-looking woman, with nervous complexion and features, black hair and bright brown eves. She was in good condition, though thinner than formerly. She had been occasionally intemperate. The organs, with the exception mentioned below, were healthy. Menstruation had been irregular lately, and for the last four years profuse. The tongue was furred, appetite poor, and bowels irregular.

She had never felt well since a miscarriage, her last pregnancy, eight years ago, and had had pain in her right side from that date. So far as she could judge, the pain had always been of the same nature as that of which she now complained. The attacks of pain started in the right side over the liver, and extended to the right shoulder and epigastrium. They were accompanied by vomiting and shivering, and made her so ill that she was obliged to stay in bed. Latterly the attacks had increased in number and sererity, so that three or four days of each week had been spent in bed. The bad fits always terminated by diarrhoea. Exercise brought on these attacks.

The lump was first discovered by herself four years ago. It was tender then, and had remained so throughout, but was worse sometimes than others. She said that it became decidedly less and not so sensitive after the purging.

Examination discovered a round, hard swelling in the position of the gall-bladder, about the size of an orange, and moving freely up and down with respiration. Puncture with a hypodermic syringe showed its contents to be the ordinary opalescent mucous fluid of a distended gall-bladder.

The operation was performed on February 29th, the tumour being exposed by a vertical incision through the abdominal parietes, immediately over it, from two to three inches long. After placing a couple of small sponges behind the distended gallbladder, an aspirator needle was introduced at the fundus, and gix ounces of opalescent fluid removed. The front wall of the gall-bladder was now drawn forwards by two pairs of ordinary
artery forceps, and opened sufficiently between them to admit easily my forefinger. Between fifty and sixty small round stones, the largest being no bigger than a pea, were scooped out with my finger, and washed out with a lligginson's syringe. The gallbladder was sponged dry, the bile-ducts explored without finding anything, and the sponges removed from the abdominal cavity.

The only serious difticulty in the operation occurred at this time. One of the sponges was lost amongst the intestines, and before $I$ could find it $I$ was obliged to enlarge the incision. In future the sponges shall be under my control with ligature or forceps. The difficulty of finding them has to be experienced to be believed. The edges of the thickened gall-bladder were now fixed to the abdominal wall, including the peritoneum, by a continuous suture, the edges of the wound brought together above and below with interrupted sutures, a rubber drainage-tube left in the bladder, and the wound dressed with carbolic gauze and a wood-wool pad. The operation throughout was conducted with antiseptic precautions.

The after-progress was uneventful. The patient got up on the ninth day, and went home some distance by rail on the seventeenth day. The wound was entirely healed at the end of five weeks, and her health is now as good as it ever was, and better than it has been for years.

\section{A CASE OF TRAUMATIC CEPIIAI-HYDROCELE.}

By F. A. SOUTHAM, M.B.Oxon., F.R.C.S.,

Assistant-Surgeon to the Manchester Roval Infirmary; Lecturer on Clinical Surgery in the Owens College.

As cases of traumatic cephal-hydrocele-the term now applied to a tumour formed by an accumulation of cerebro-spinal fluid beneath the scalp, occurring as a complication of simple fracture of the vault of the skull-are somewhat rare, the following instance is perhaps worthy of record.

The patient, a male cliild, aged 6 months, was admitted into the hospital under my colleague, Mr. Heath, on December 28th, 1887, suffering from an injury to the head, the result of a fall down a flight of stairs the previous evening. The mother stated that when taken up the child was in an unconscious state, and re-

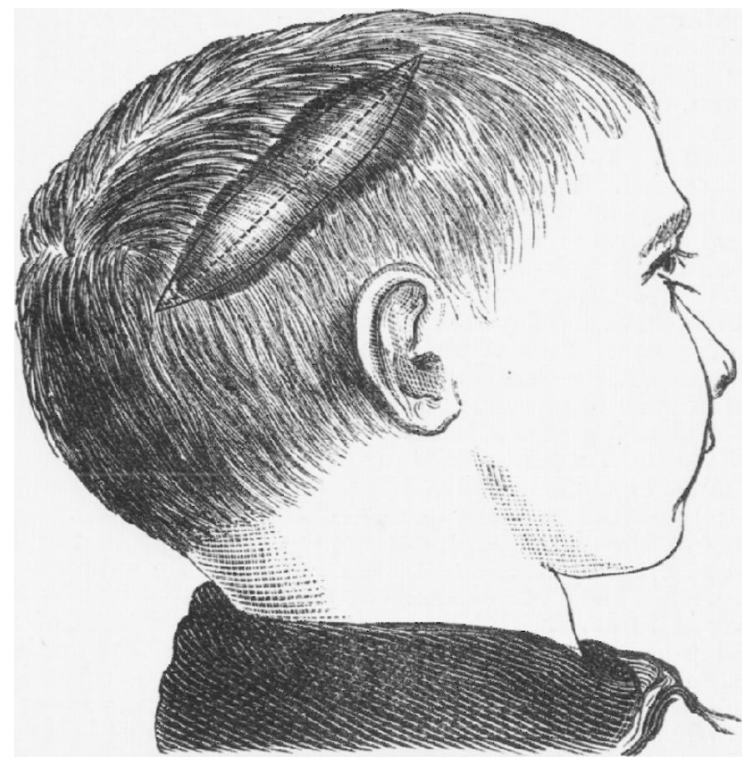

mained so during the night. On admission the following morning he was sensible, though somewhat drowsy; there was right ptosis, with slight conjugate deviation of the eyeballs towards the right side; the pupils were equal, neither contracted nor dilated. On examining the head a fracture was found running obliquely across the parietal and occipital region on the right side, causing a deep, oval, gutter-shaped depression, two inches and a half in length, one inch in width. There was no bruising of the skin, and no 
swelling beyond a little puffiness of the tissues of the scalp over and around the seat of fracture. In the course of a fow days the child became bright and lively, the deviation of the eyeballs and the prosis disappeared, and on January 8th he was discharged from the hospital apparently quite well, no swelling being perceptible in the region of the fracture, the depression of which was still evident.

Four days later, on January 12th, the child was brought to my out-patient room, when I saw him for the first time, and on examining the head a distinct swelling was apparent immediately over the seat of fracture. The swelling was oval in shape, about two inches in length, one inch and a quarter in breadth, and slightly constricted at its middle, its long axis running parallel with the direction of the fracture; it was raised about threequarters of an inch above the level of the surrounding surface, and was soft and fluctuating; it exhibited distinct pulsation syuchronous with that felt at the anterior fontanelle, was partiully reducible on pressure, and became fuller and more tense when the child cried; the skin covering it presented a normal appearance. The fracture could be felt beyond the anterior and posterior margins of the tumour, and, after partially emptying the latter by external pressure, the depression of the bone beneath could also be distinguished. The child, though somerwhat dull and drowsy, presented no other symptoms. The only treatment adopted consisted in applying moderate pressure over the tumour by means of a pad of lint and bandage.

January 19th. The swelling was somewhat diminished in size, and the pulsation less distinct.

January 24th. The pulsation had quite ceased; the tumour was much smaller and softer; it still became more tense when the child cried, and was only reducible after prolonged pressure.

February 15th. The swelling had entirely disappeared and the child appeared to be enjoying perfect health ; there was still a marked depression in the bone along the line of fracture.

The condition, of which the foregoing case is a good illustration, was first fully described by Mr. Clement Lucas, in the Guy's Hospital Reports for 1876; since that date other instances have been recorded both by himself and other surgeons. Lucas believes that the cerebro-spinal fluid escaping through the fracture in the vault of the skull comes, not as one would suppose, from the subarachnoid space, but from the lateral ventricle, owing to the laceration of brain substance which accompanies the injury to the head involving the ventricular cavity. In two instances he has been able to verify this opinion by post-mortem examination, and in two other recorded cases a similar communication has been found to exist.

The present case, to some extent, supports this riew, for the deep in-driving of the bone at the seat of fracture would almost necessarily be accompanied by a wound of the dura mater, while from the nature of the injury and the symptoms which the child afterwards presented, it is probable that some laceration of brain substance was also produced. The fact that the swelling did not appear until after an interval of thirteen days also agrees with the period at which the tumour has first sliown itself in other cases, and Lucas suggests that the inflammation which follows the injury to the brain is accompanied by softening of the cerebral substance and increased secretion of cerebro-spinal fluid, " so that pressure from within and yielding of the brain-wall together contribute to the escape of fluid from the ventricle:" it accordingly accumulates beneath the scalp in the form of a distinct tumour, which, owing to its communication with the interior of the cranium, presents the characteristic symptoms already described. The absence of any cerebral symptoms at the time the tumour appeared is accounted for by the very young age of the child, for it is a recognised fact that in infants extensive mischief may be going on in the brain, without producing the same marked symptoms which would usually be present in an adult.

The cessation of the pulsation, and the difficulty in reducing the tumour after the twenty-eighth day, were probably owing to the gradual closure of the fissure in the bone cutting off the communication with the interior of the cranium, and the gradual disappearance of the swelling after that date was the result of absorption of the fluid by natural means, assisted by the application of external pressure.

According to Conner (American Journal of the Medical Sciences, July, 1884), the prognosis in traumatic cephal-liydrocele is very unfavourable, half the recorded cases (which up to 1881 were seventeen in number) having terminated fatally from the supervention of meningitis. The accompanying sketch illustrates the shape and situation of the tumour, and its relation to the subjacent fracture, the outline of which is indicated by the dark lines.

\section{A CONTRIBU'TION 'TO THE S'TATIS'TICS' OF STONE OPERATIONS.}

BY JOSEP II PROCIINOV, M.D., Buda-Pesth.

Nor long ago the excellent work of Sir Henry Thompson, On the Surgery of the Urinary Organs, translated into German by Dr. E. Dupuis (Wiesbaden, 1885), came into my hands, and in the last lecture (p. 149) I read the following lines: "It is the sum total of result obtained by employing the two procerlures which is to be regarded as the measure of the surgeon's success. And I think 1 may say that a list of 782 cases in mule adults, the mean of whose united ages exceeds 60 years, with 82 deaths, or 1 in $91 \frac{1}{2}$ cases, is a result which will be held to justify the selection and adaptation of the method to the case, which has been adopted throughout this series. I venture to say that it is a result which has not, certainly to my knowledge, hitherto been realised."

Professor Kovács, at Buda-Pesth, has recently published his stone operations. It is true that Sir H. Thompson is able to show larger numbers, but the statistical data of Professor Kovícs give a result which is a little better than Sir H. Thompson's.

Sir H. Thompson, on 716 patients, performed altogether 812 operations, with 84 deaths (10.3 per cent.). His cases are divided in the following manner:

13 femule patients :

10 lithotomies, with 1 death.

15 children:

3 lithotrities - -

12 lithotomies, with 1 death.

2 extractions.

3 lithotrities - - -

If these 30 cases are deducted, there remain 782 cases of male adults.

110 lithotomies, with 39 deaths, 35 per cent.
672 lithotrities " $\frac{43}{82} " \frac{6.5}{10.5}$
Total

At the First Surgical Clinic Professor Korács, on 233 patients, performed 248 operations, with 21 and 18 deaths respectively ( 8.5 per cent. and 7.25 per cent.). There were:

77 sectio perinealis lateralis, with 4 deaths.

2 sectio alta $" 1$

168 Jithotrities

" 16

1 extractio calculorum

But it must be remarked that among the cases treated by lithotrity there were 3 who died of intercurrent diseases-namely, one putient of 14 years died of apoplexia cerebelli, one patient of 67 years of cholera Asiatica, and one patient of 48 years of pneumonia. If these cases are deducted, as seems to be reasonable, the mortality becomes less.

The cases of Professor Kovács, classified in the same way as Sir H. Thompson's, give the following result :

13 female patients: all 13 lithotrities

115 children (namely patients under 20 years) 70 lithotomies, with 2 deaths. 75 lithotrities "(4) 3 ",

1 extractio calculorum

and 2 sectio alta

(The two cases of sectio alta" are cited separately, because Sir II. Thompson did not mention any cases of sectio alta amongst the lithotomies of male adult patients.)

These 131 cases deducted, there remain 117 male adults treated by lithotomy and lithotrity-namely:

7 lithotomies, with 2 denths, 28.5 per cent.

110 lithotrities "(12) $10, "$ (10.9 per cent.) 9 per cent.

Total $\overline{117} \overline{(14) 12} \quad \overline{(11.9 \text { per cent.) } 10.2 \text { per cent. }}$ Consequently, from this combination, it is clear :

1. In the female patients lithotrity was performed without a death.

2 In children-namely, patients under 20 years-lithotomy (sectio perinealis) was performed 70 times, with only 2 deaths; 